Provided for non-commercial research and education use. Not for reproduction, distribution or commercial use.

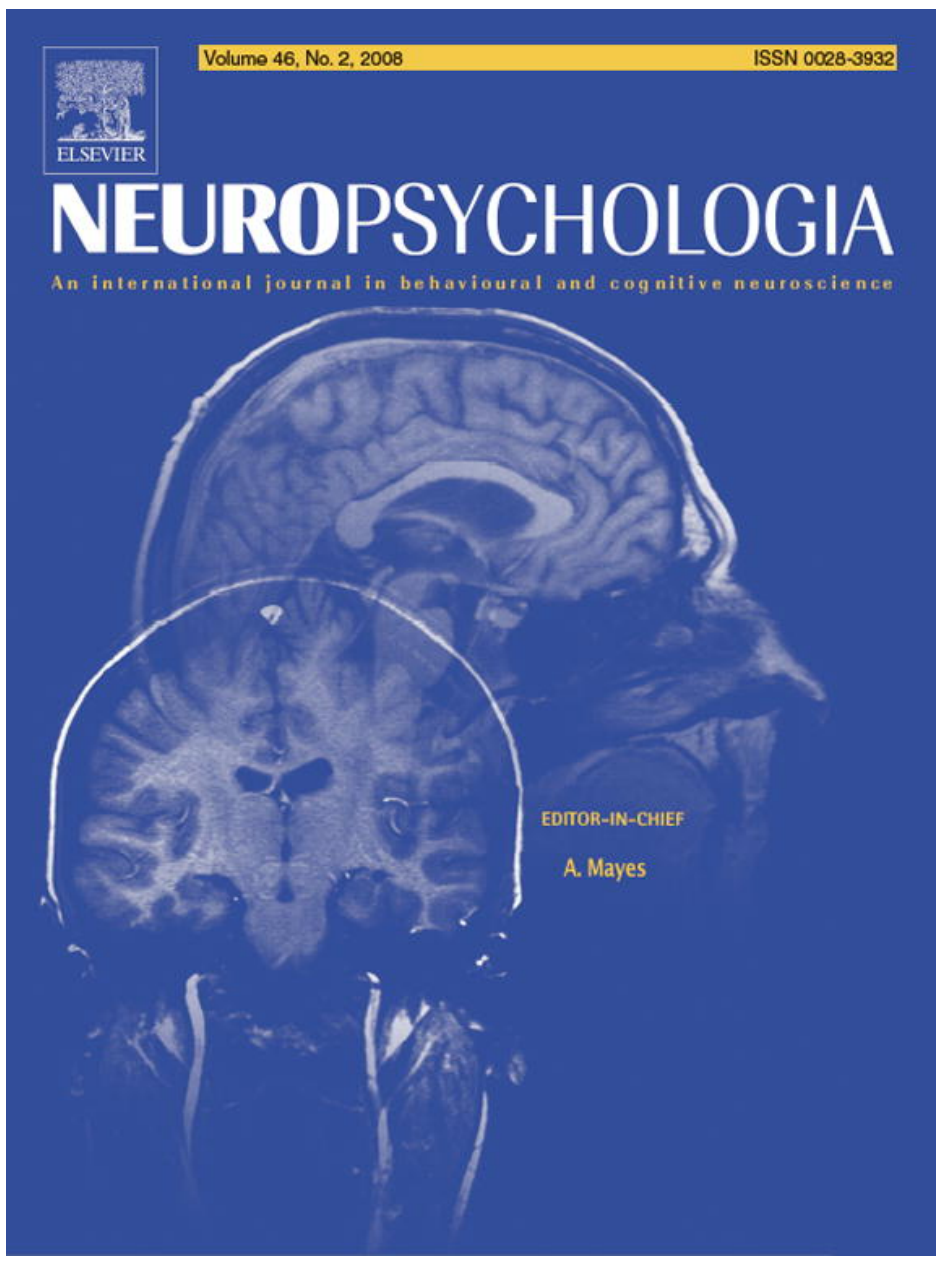

This article was published in an Elsevier journal. The attached copy

is furnished to the author for non-commercial research and education use, including for instruction at the author's institution, sharing with colleagues and providing to institution administration.

Other uses, including reproduction and distribution, or selling or licensing copies, or posting to personal, institutional or third party websites are prohibited.

In most cases authors are permitted to post their version of the article (e.g. in Word or Tex form) to their personal website or institutional repository. Authors requiring further information regarding Elsevier's archiving and manuscript policies are encouraged to visit: 


\title{
Deficits of knowledge versus executive control in semantic cognition: Insights from cued naming
}

\author{
Elizabeth Jefferies ${ }^{\mathrm{a}, *}$, Karalyn Patterson ${ }^{\mathrm{b}}$, Matthew A. Lambon Ralph ${ }^{\mathrm{c}}$ \\ a Department of Psychology, University of York, York YO10 5DD, UK \\ ${ }^{\mathrm{b}}$ MRC Cognition and Brain Sciences Unit, Cambridge, UK \\ ${ }^{\mathrm{c}}$ University of Manchester, $U K$
}

Received 26 March 2007; received in revised form 4 September 2007; accepted 11 September 2007

Available online 18 September 2007

\begin{abstract}
Deficits of semantic cognition in semantic dementia and in aphasia consequent on CVA (stroke) are qualitatively different. Patients with semantic dementia are characterised by progressive degradation of central semantic representations, whereas multimodal semantic deficits in stroke aphasia reflect impairment of executive processes that help to direct and control semantic activation in a task-appropriate fashion [Jefferies, E., \& Lambon Ralph, M. A. (2006). Semantic impairment in stroke aphasia vs. semantic dementia: A case-series comparison. Brain 129, 2132-2147]. We explored interactions between these two aspects of semantic cognition by examining the effects of cumulative phonemic cueing on picture naming in case series of these two types of patient. The stroke aphasic patients with multimodal semantic deficits cued very readily and demonstrated near-perfect name retrieval when cumulative phonemic cues reached or exceeded the target name's uniqueness point. Therefore, knowledge of the picture names was largely intact for the aphasic patients, but they were unable to retrieve this information without cues that helped to direct activation towards the target response. Equivalent phonemic cues engendered significant but much more limited benefit to the semantic dementia patients: their naming was still severely impaired even when most of the word had been provided. In contrast to the pattern in the stroke aphasia group, successful cueing was mainly confined to the more familiar un-named pictures. We propose that this limited cueing effect in semantic dementia follows from the fact that concepts deteriorate in a graded fashion [Rogers, T. T., Lambon Ralph, M. A., Garrard, P., Bozeat, S., McClelland, J. L., \& Hodges, J. R., et al. (2004). The structure and deterioration of semantic memory: A neuropsychological and computational investigation. Psychological Review $111,205-235]$. For partially degraded items, the residual conceptual knowledge may be insufficient to drive speech production to completion but these items might reach threshold when they are bolstered by cues.
\end{abstract}

(C) 2007 Elsevier Ltd. All rights reserved.

Keywords: Semantic dementia; CVA; Stroke; Aphasia; Picture naming; Cueing; Semantic memory; Executive control

\section{Introduction}

Impairments of semantic cognition in different neuropsychological populations can reflect a number of distinct underlying impairments. (1) There may be degradation of semantic knowledge itself, as in semantic dementia (SD). (2) Patients with agnosia or pure word deafness have difficulty accessing intact semantic knowledge from a particular input modality. (3) Other stroke aphasic patients show multimodal comprehension problems that are associated with poor cognitive control. For ease of reference, we will adopt the term 'semantic aphasia' (SA)

\footnotetext{
* Corresponding author. Tel.: +44 1904 434368; fax: +44 1904433181.

E-mail address: ej514@york.ac.uk (E. Jefferies).
}

for this latter group. Although patients with SD and SA can fail the same verbal and non-verbal semantic tasks, research suggests that the comprehension disorder in these two conditions is qualitatively different (Jefferies \& Lambon Ralph, 2006). These patients also have very different areas of brain damage: $\mathrm{SD}$ is characterised by bilateral atrophy and hypometabolism of the anterior temporal lobes (Nestor, Fryer, \& Hodges, 2006), whereas poor comprehension in SA is associated with left prefrontal and/or temporoparietal infarcts (e.g., Chertkow, Bub, Deaudon, \& Whitehead, 1997). Studies that compare the nature of the semantic deficit in these two conditions may therefore provide insights into the neural and functional organisation of semantic cognition.

Patients with SD have a highly specific, progressive degradation of semantic knowledge that we have previously labelled 
“dimmed" representations (Jefferies \& Lambon Ralph, 2006): they fail diverse semantic tasks even though other aspects of cognition and language such as phonology, visual processing and decision-making remain intact (Bozeat, Lambon Ralph, Patterson, Garrard, \& Hodges, 2000; Hodges, Patterson, Oxbury, \& Funnell, 1992; Snowden, Goulding, \& Neary, 1989). The SD patients' degradation of amodal semantic representations leads to substantial deficits in non-verbal and verbal expressive tasks including speech production; indeed, profound anomia is often the first and major presenting symptom (Lambon Ralph, Graham, Ellis, \& Hodges, 1998; Lambon Ralph, McClelland, Patterson, Galton, \& Hodges, 2001). Critically, semantic knowledge degrades in a gradual and structured fashion (Rogers et al., 2004) and the degree of semantic impairment observed in any task is strongly influenced by the frequency/familiarity of the concepts being assessed (Bozeat et al., 2000; Funnell, 1995; Lambon Ralph et al., 1998).

SA patients can also show semantic deficits across a range of input/output modalities (Chertkow et al., 1997; Hart \& Gordon, 1990; Saygin, Dick, Wilson, Dronkers, \& Bates, 2003) but the nature of the semantic impairment is different from that seen in SD. Comprehension impairment in a number of stroke aphasic cases has been characterised as "semantic access impairment" in contrast to the "semantic storage deficits" in SD. These patients (a) are largely insensitive to item frequency, (b) are item-inconsistent when semantic tests are repeated, and (c) show "refractory" effects: i.e., performance is poorer for a short time after the retrieval of conceptual knowledge, particularly when semantically related items are presented repeatedly (e.g., Crutch \& Warrington, 2005; Forde \& Humphreys, 1995; Warrington \& Cipolotti, 1996).

Our recent studies using a case-series design directly compared SD patients with SA patients who were selected as having semantic deficits on non-verbal as well as verbal tasks (Jefferies, Baker, Doran, \& Lambon Ralph, 2007; Jefferies \& Lambon Ralph, 2006). Although the two patient groups obtained broadly equivalent scores on semantic tests, they showed qualitatively different deficits. The SD patients showed substantial consistency when a set of items was assessed across different semantic tests and were highly sensitive to frequency in a range of tasks. In picture naming, they made coordinate (cow $\rightarrow$ "horse") and superordinate (cow $\rightarrow$ "animal") errors. These findings are consistent with the view that SD patients have degraded amodal semantic knowledge (Bozeat et al., 2000; Rogers et al., 2004). The SA patients, in contrast, did not perform consistently on tasks that required different types of semantic judgement (e.g., simple matching tasks vs. judgements of semantic association) even when the same concepts were probed, suggesting that their deficits did not stem from a loss of central knowledge. They often succeeded in retrieving the semantic information required for one task, but then were unable to reshape the information to meet the requirements of another test/situation. Their performance deteriorated when a small set of semantically related items was repeated several times, and they were insensitive to item frequency, showing that their comprehension impairment had a refractory quality. They also made semantic errors in picture naming of an associative nature (e.g., squir- rel $\rightarrow$ "nuts"; glass $\rightarrow$ "ice"; lorry $\rightarrow$ "diesel"), an error type almost never observed in SD. This suggests that the SA patients retained a considerable amount of semantic information about the un-named items but had difficulty overcoming strong, taskirrelevant semantic associations.

These results suggest that semantic cognition is underpinned by (at least) two interacting components: amodal semantic representations and control processes. Our hypothesis is, firstly, that aspects of knowledge specific to particular sensory or motor modalities (e.g., knowing that the outside of a lemon is yellow, that the juice inside it is tart, that the juice can be extracted by squeezing) depend upon a widespread network of modality-specific brain regions. Higher-order amodal semantic representations - which enable both generalisation and differentiation between similar concepts and cross-talk between different modalities - are formed in the anterior temporal lobes and become degraded in SD. The Rogers et al. (2004) model provides an instantiation of this hypothesis (see Damasio, Tranel, Grabowski, Adolphs, \& Damasio, 2004; Martin, Haxby, Lalonde, Wiggs, \& Ungerleider, 1995; Wernicke, 1874, for related theories). Furthermore, we hypothesise that these highlevel semantic representations interact with executive processes that help to direct and control semantic activation in a taskappropriate fashion. These executive processes are critical to good performance on semantic tasks because we know many different things about any given object or concept, and only particular aspects of our knowledge are relevant for a specific task or context (Saffran, 2000). It is this aspect of semantic cognition that we suggest is impaired in SA.

In the current study, we explored interactions between these two components of semantic cognition - amodal concept knowledge and semantic control - by examining the effect of cueing on picture naming. Cues should boost activation of the target word relative to semantically related competitors and consequently might overcome the SA patients' difficulties in regulating semantic activation. For example, if the prepotent associate "nuts" is activated in response to a picture of a squirrel, this error will be inconsistent with the initial phonemic cue/s/; and if the further sounds of the target name are progressively added in the cueing procedure (/s@/, /sk@/, /skw@/, /skwI/, etc.), the field of competing responses will rapidly narrow until only the target is left. This prediction can be placed in the context of the interactive-activation model of language processing proposed by Dell and colleagues (Dell \& O'Seaghdha, 1992; Dell, Schwartz, Martin, Saffran, \& Gagnon, 1997; Foygel \& Dell, 2000; Schwartz, Dell, Martin, Gahl, \& Sobel, 2006). According to this account, there are bi-directional connections between semantic, lexical and phonological nodes involved in picture naming. Consequently, cues that activate some of the target phonemes will combine with activation in the semantic layer, boosting semantic activation for the target and dampening down activation of competitors. Cueing might be less beneficial in SD because these patients do not have difficulties directing their residual semantic activation appropriately, and/or because there is less semantic activation with which a cue can combine. Pictures of semantically degraded items are likely to generate either very little activity in the semantic system or responses that are 
general and prototypical (e.g., "fruit" for orange). Consequently, phonemic cues are less likely to raise target responses to threshold level.

Whilst our previous study (Jefferies \& Lambon Ralph, 2006) provided some evidence to suggest that SA patients are more responsive than SD patients to phonological cues, the SD group were at floor on the naming test that we used, both with and without cues (Boston Naming Test, Kaplan, Goodglass, \& Weintraub, 1983). Individuals with SD might be more responsive to cues if tested on higher frequency items that are less semantically degraded. In the present investigation, we directly compared the effect of phonemic cueing in semantically impaired patients with SD versus SA using a set of easier items that were more appropriate for an SD sample. We assessed a case-series of SD patients who varied substantially in the severity of their semantic impairment. These were compared with a subset of the SA patients studied previously by Jefferies and Lambon Ralph (2006). In place of phonological cues of a standard length (e.g., two phonemes as in our previous study), we used a cumulative cueing procedure in which the size of the phonological cue was increased one phoneme at a time (Graham, Patterson, \& Hodges, 1995; Lambon Ralph, 1998; Lambon Ralph, Cipolotti, \& Patterson, 1999; Patterson, Purell, \& Morton, 1983). This allowed us to investigate whether SD patients do cue to some extent when provided with enough of the target phonology.

\section{Participants}

Six of the 10 SA patients studied by Jefferies and Lambon Ralph (2006) were included in this study. Two patients with extremely limited speech production were not tested. A further two cases were at or near ceiling for uncued picture naming on this relatively high-frequency set of items and were therefore excluded from the analysis. Every case had chronic impairment from a CVA at least a year previously. All of the aphasic patients were selected to show multimodal semantic deficits. Four were transcortical sensory aphasic (TSA) patients with poor comprehension in the context of fluent speech and good repetition; these cases had an aphasia profile that superficially resembles that seen in SD. The remainder had less fluent speech and/or poorer repetition relative to the degree of comprehension impairment (see Table 1 for demographic details and aphasia classifications from the Boston Diagnostic Aphasia Examination). All of the patients were largely accurate when repeating single words, suggesting that they would have been able to process the spoken cues during picture naming.

Neuroradiology for the SA cases is shown in Fig. 1 and Table 1 summarises the lesion for each aphasic stroke patient. MR images were available for four cases (SC, ME, KH2 and LS) and CT was available for one more (BB). It was not possible to obtain scans for one patient (JM) due to a lack of consent or contraindications for MRI, although a written report of a previous CT scan was available. In line with the literature on semantic impairment in SA, all of the patients had left temporoparietal and/or prefrontal lesions (Berthier, 2001; Jefferies \& Lambon Ralph, 2006).

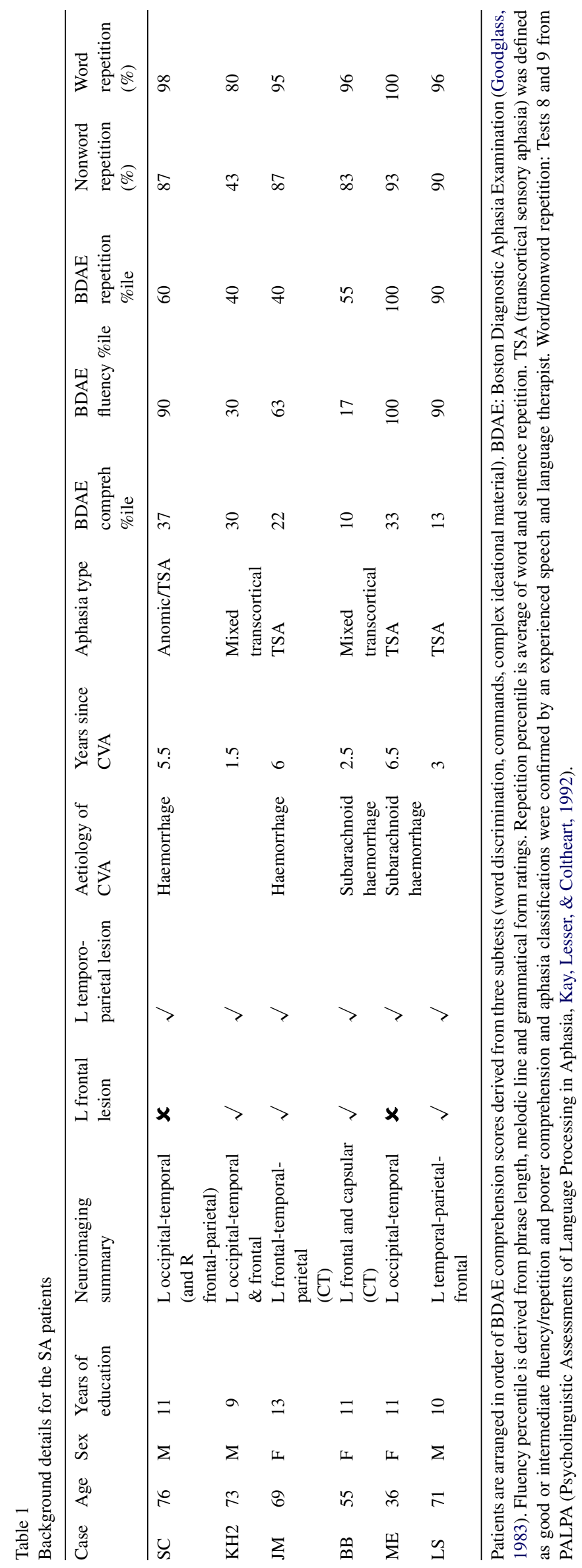



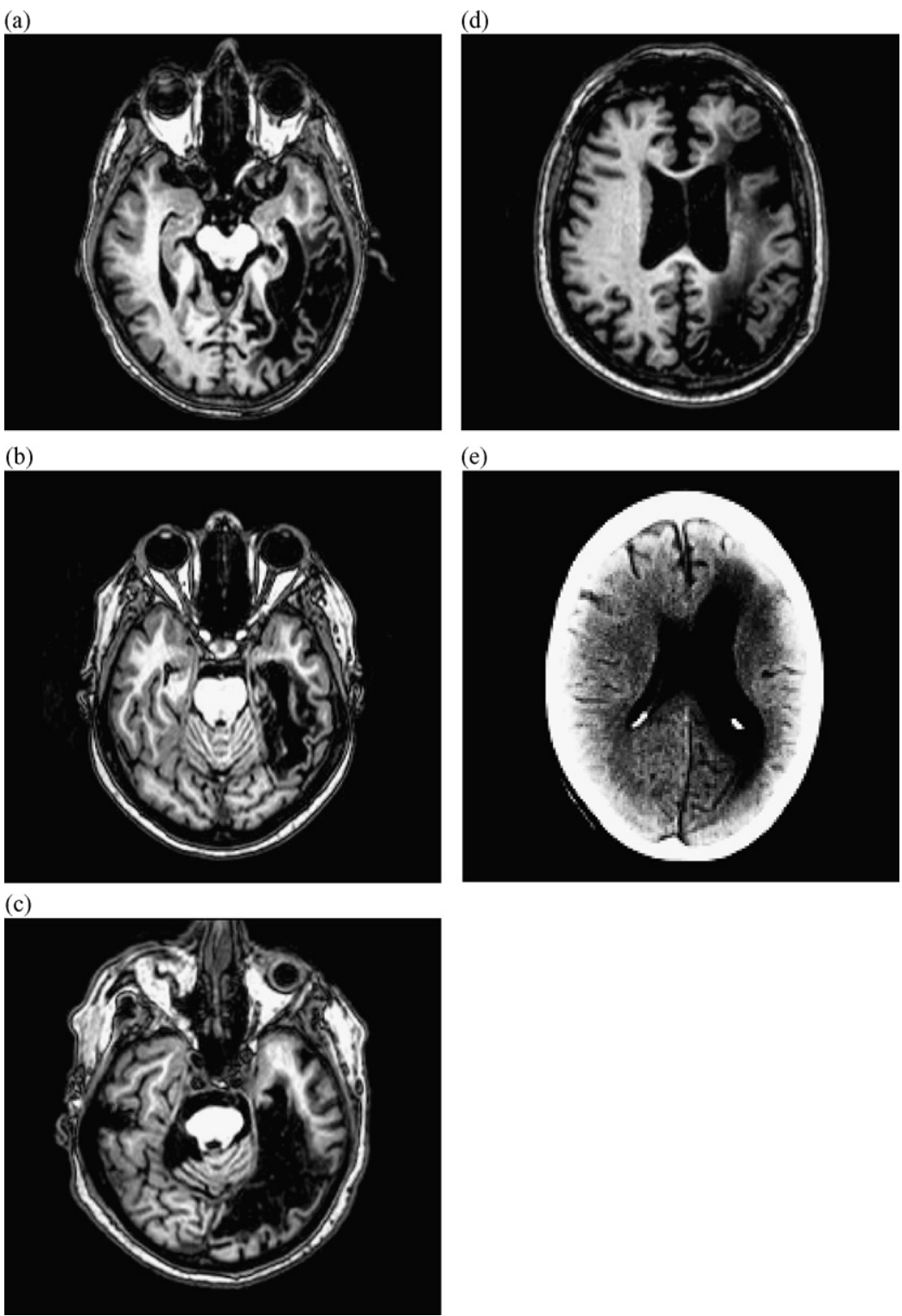

Fig. 1. Neuroradiology for the SA patients. (a) SC, (b) ME, (c) (KH), (d) LS and (e) BB.

The SD cohort included eight cases recruited from Cambridge, Bath or Liverpool, UK. The patients fulfilled all of the published criteria for SD (e.g., Hodges et al., 1992): that is, they had deficits in all semantic tasks administered, whether verbal or non-verbal and receptive or expressive; but other aspects of cognition such as visual-spatial abilities and day-to-day memory were relatively well preserved. MRI revealed focal atrophy of the anterior and inferior aspects of the temporal lobes bilaterally in every case. See Table 2 for demographic details and dementia severity for the SD group.

\section{General neuropsychology}

\subsection{Assessments}

General neuropsychological assessments included forwards and backwards digit span (Wechsler, 1987), the Visual Object and Space Perception battery (Warrington \& James, 1991) and the Coloured Progressive Matrices test of non-verbal reasoning (Raven, 1962). The SA cases were given additional tests of attention and executive skill: the Wisconsin Card Sort test

Table 2

Background details for the SD patients

\begin{tabular}{llllll}
\hline Case & Age & Sex & Education (leaving age) & Years post onset & MMSE \\
\hline SJ & 59 & F & 11 & 2 & 23 \\
JC & 58 & M & 10 & 6 & 15 \\
EK & 59 & F & 10 & 4 & 27 \\
KH1 & 61 & M & 14 & 6 & 10 \\
AT & 66 & M & 19 & 4 & 24 \\
GT & 71 & M & 9 & 5 & 22 \\
GE & 49 & M & 11 & 2 & 13 \\
PD & 72 & F & 9 & 8 & $1975)$. \\
\hline
\end{tabular}

MMSE: Mini-mental State Examination (Folstein, Folstein, \& McHugh, 1975). 
(WCST; Milner, 1964; Stuss et al., 2000), the Brixton Spatial Rule Attainment task (Burgess \& Shallice, 1996), the Hayling sentence completion test (Burgess \& Shallice, 1997) and the Elevator Counting subtests with and without distraction from the Test of Everyday Attention (Robertson, Ward, Ridgeway, \& Nimmo-Smith, 1994).

Semantic processing was assessed with a number of tests. (1) In the Pyramids and Palm Trees Test (PPT), subjects decide which of two items is more associated with a target-e.g., does PYRAMID go with PINE TREE Or PALM TREE (Howard \& Patterson, 1992). (2) The patients were given a semantic battery designed to assess knowledge of a set of 64 items from the Snodgrass and Vanderwart (1980) set across different input and output modalities (Bozeat et al., 2000). There were four tasks: naming line drawings; word-picture matching using an array of 10 items from the same semantic category; and word and picture versions of the Camel and Cactus Test (CCT) which, like the PPT, examined judgements of semantic association. (3) We assessed category fluency (for six categories; animals, birds, fruit, household items, tools and vehicles) and letter fluency (using the letters F, A, S). In both fluency tests, participants produced as many exemplars as possible in $1 \mathrm{~min}$.

\section{Results}

The SD patients showed a pattern of selective semantic impairment: they had normal digit spans and relatively good non-verbal reasoning (see Table 3 ). The SA patients performed poorly on the same range of verbal and non-verbal semantic tasks but were also impaired on a variety of attentional/executive measures. Indeed, comprehension impairment in the SA group correlated with executive dysfunction (Jefferies \& Lambon Ralph, 2006).

In every table/graph below, the patients within each group are arranged in ascending order of the severity of semantic impairment as indicated by a composite score. This score was derived using factor analysis from the first four semantic tasks in Table 2, for which scores were available for all participants (word and picture PPT, picture naming and word-picture matching).

\section{Progressive phonological cueing experiment}

\subsection{Method}

There were 30 individual pictures from the Snodgrass and Vanderwart (1980) set, 10 each with one, two or three syllable names (see Appendix A for details). The patients first attempted to name each picture spontaneously. For items they could not name, they were given phonemic cues cumulatively, adding one phoneme at a time, starting with the first phoneme. Cueing was terminated when the patient produced the correct response or when all the target phonemes had been provided.

\subsection{Results}

\subsubsection{Spontaneous naming accuracy}

There was substantial variation in the severity of the spontaneous naming impairment for both patient groups (see Fig. 2). Uncued naming performance did not differ significantly for the SD and SA patients $(t<1)$. There was a strong correlation between the composite semantic score (see Table 2) and spontaneous picture naming for both the SD group ( $r=.89$, onetailed $p=.002)$ and the SA group $(r=.80$, one-tailed $p=.03)$. The SD group also showed a significant correlation between word frequency and naming accuracy in terms of the proportion of patients who were able to name each item $(r=.39$, one-tailed $p=.02$ ). This correlation approached significance for the SA group $(r=.27$, one-tailed $p=.08)$. Frequency data were taken from the Celex database (Baayen, Piepenbrock, \& van Rijn, 1993).

\subsubsection{Effect of phonological cueing}

Fig. 2 also displays the effect of cumulative phonological cueing for the SD and SA groups. Performance in both groups improved when phonemic cues were provided. Naming was more accurate with a two-phoneme cue versus no cue (SD group: $t(7)=4.5, p=.003$; SA group: $t(5)=4.2, p=.009)$ and was even better following the final phonological cue-i.e., the whole word minus the last phoneme (compared with the two-phoneme cue; SD group: $t(7)=3.8, p=.006$; SA group: $t(5)=2.7, p=.04)$.

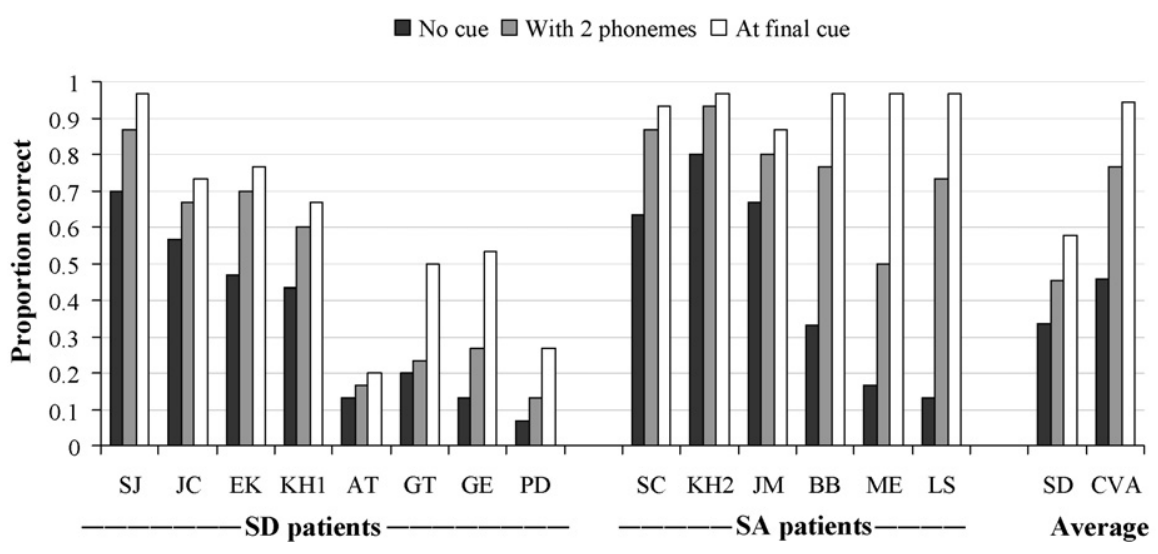

Fig. 2. Impact of progressive phonemic cueing on naming performance. 
Table 3

Neuropsychological assessments

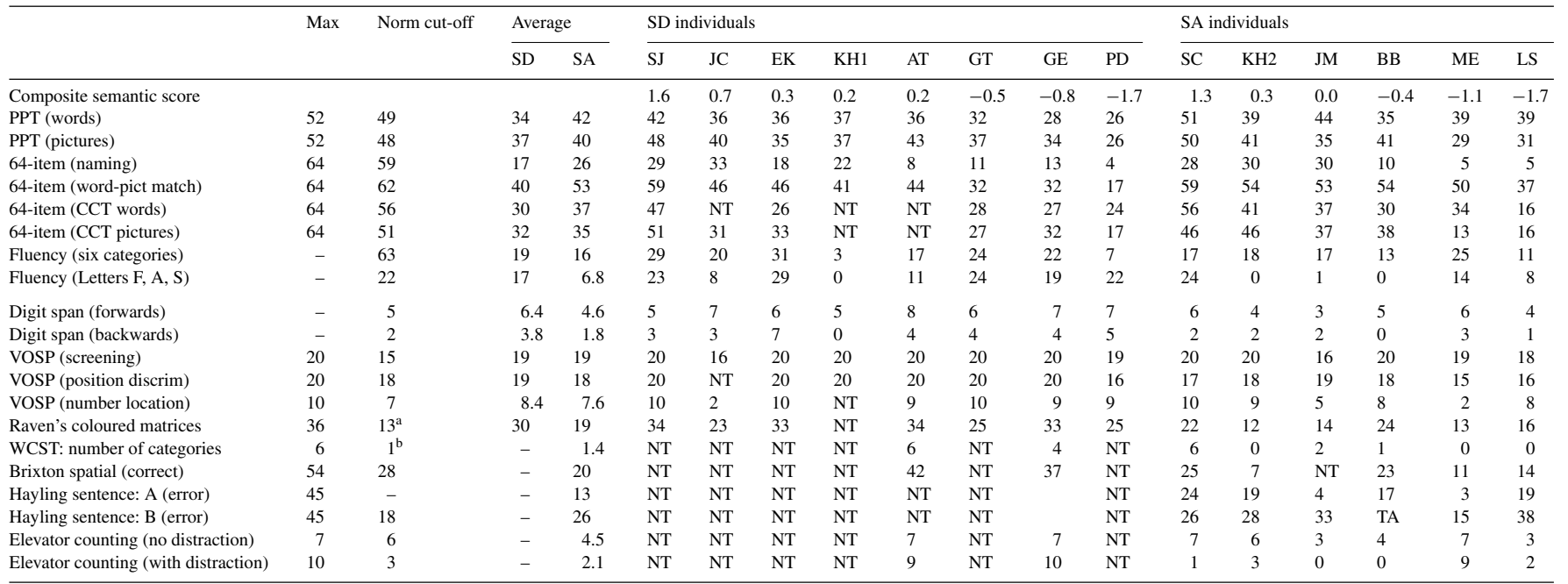

Patients are arranged in order of overall semantic score. Semantic scores for AT are an average of two testing rounds. NT: not tested; TA: testing abandoned; PPT: Pyramids and Palm Trees Test (Howard \& Patterson, 1992); CCT: Camel and Cactus Test (Bozeat et al., 2000); VOSP: Visual Object and Space Perception battery (Warrington \& James, 1991); WCST: Wisconsin Card Sort Test (Milner, 1964; Stuss et al., 2000). a 5 th percentile at age 70 .

b Cut-off for 50-74 year olds (regardless of educational level). 
The SA patients showed a significantly larger cueing effect than the SD group, when spontaneous naming was compared with either the two-phoneme cue $(F(1,12)=8.0, p=.02)$ or the final cue $(F(1,12)=5.0, p=.05)$. When the SD patients were successfully cued, they also required significantly more of the target phonology than the SA patients (an average of 54\% vs. $40 \%$ of the phonemes in the target word; $t(12)=2.7, p=.02$ ). Fig. 2 indicates that the SD patients were still severely anomic following the final cue. The group averages show that (a) after a two-phoneme cue, the SD patients on average only achieved the level of naming success that characterised uncued naming for the SA group as a whole; and (b) at the final cue, the SD patients' success on average was still considerably lower than the SA average following two-phoneme cues. Due to the effectiveness of cueing for the SA patients, their name retrieval was at or near ceiling following the final cue for every case, including those individuals who were profoundly impaired without cues.

Every individual SA patient showed significantly better naming following the final cue (pre- and post-cue naming was compared using McNemar; $p=.03$ to <.0001). The SA patients also showed a benefit from the two-phoneme cue that was significant or nearly so in each individual (McNemar $p=.06$ to .0002 ). All but one of the SD patients showed an advantage following the final cue (McNemar $p=.03$ to .0002), and half of the cases were significantly cued by two phonemes $(\mathrm{McNemar} p=.06$ to .0002).

The SD patients cued more readily for high compared with low frequency items. There was a significant correlation between word frequency and the proportion of each word's phonology that was required for the SD patients to cue $(r=-.38$, twotailed $p=.05)$, probably reflecting the relationship of concept frequency/familiarity to degree of retained conceptual knowledge. In contrast, the SA cases did not show this effect $(r=-.15)$, most likely because frequency does not have a strong influence on comprehension/knowledge in SA (Jefferies \& Lambon Ralph, 2006).

\section{Discussion}

This study examined the impact of progressive phonological cueing on the retrieval of picture names in two groups of patients with comprehension impairment: patients with semantic dementia (SD) and patients with multimodal semantic deficits following stroke ("semantic aphasia" or SA). Although cues have been found to facilitate name retrieval in aphasic patients (e.g., Myers Pease \& Goodglass, 1978; Podraza \& Darley, 1977), there have been virtually no published investigations of the effect of such cues in SD (see Graham et al., 1995, for an exception). Semantic impairment in these two conditions is associated with very different areas of brain damage (bilateral anterior temporal lobe atrophy in SD vs. left prefrontal or temporoparietal lesions in SA; Berthier, 2001; Chertkow et al., 1997; Jefferies \& Lambon Ralph, 2006). In line with this neuroanatomical distinction, there are qualitative differences in the nature of the semantic deficit in SD and SA which suggest damage to two separable but interacting components of semantic cognition: SD patients have degraded semantic representations, while SA cases have poor executive control of semantic processing that disrupts the ability to use semantic knowledge in a flexible and task-appropriate manner (Jefferies \& Lambon Ralph, 2006).

Because of these different underlying impairments, we predicted that phonemic cues - which boost activation of the target word relative to potential competitors - should improve naming in SA more than in SD. Our results confirmed these expectations. SA patients cued more readily than the SD patients: they displayed much greater improvements in naming following phonemic cueing and they required less of the target phonology to cue. Indeed, the SA patients were able to achieve near-ceiling accuracy when provided with enough of the target phonology. In contrast, the SD patients showed a considerable degree of anomia even when provided with the entire word minus the last phoneme as a cue.

Patients with SD have a profound anomia because whatever partial semantic knowledge remains is insufficient to engender production of the correct object name (Lambon Ralph et al., 2001). We suggest that when an SD patient is asked to name a picture of a camel for example, one of the following often happens. (a) The picture generates so little coherent activation in the semantic system that no candidate phonological representation rises above floor-level activation. In this case, when the experimenter says/kae/or even/kaem/, there is no additional phonological information deriving from semantics with which this phonemic cue can combine. On the basis of the cue, which is the only phonological information available, the word could just as plausibly be "camera" as "camel". (b) Some coherent activation occurs in the semantic system, but it is general and prototypical rather than specific, such that "horse" or "animal" are more likely responses than "camel". In this case, the phonemic cue for "camel" is not congruent with the fledgling phonological activation deriving from the semantic system. In contrast, SA patients with poor semantic control should be highly sensitive to cues. This is because cues act as external constraints on semantic and phonological activation, reducing the need for internally generated control. If conceptual knowledge is relatively intact in SA despite these patients' poor semantic control, cues may overcome failures of semantic retrieval to produce near-perfect performance.

Naming by the SD patients did benefit to a limited but significant degree with cues. It seems likely that this partial benefit follows from the fact that concepts deteriorate in a graded fashion (Rogers et al., 2004). For a certain range of semantic impairment (governed by the severity of the patient and the degree of item-specific degradation), correct target information may be partially activated but the remaining conceptual knowledge may be insufficient to drive speech production to completion. These items might reach threshold when they are bolstered by cues. As expected from the combination of this explanation and the fact that semantic degradation in SD is so strongly modulated by frequency or familiarity (Bozeat et al., 2000; Funnell, 1995; Lambon Ralph et al., 1998), we observed a correlation between frequency and the proportion of phonology which was required to cue. However, further research is required to investigate whether individual SD patients cue more readily for un-named items that they can still partially understand on semantic tests. 
Phonemic cueing effects are likely to be curtailed by deficits of phonological processing: successful cueing requires the cue to be accurately perceived and then manipulated in order to combine it with phonological activation generated by the picture. SD patients do not show phonological problems at least until the late stages of the disease (Jefferies, Jones, Bateman, \& Lambon Ralph, 2005; Jefferies, Patterson, Bateman, Jones, \& Lambon Ralph, 2006). However, SA can markedly impair phonological processing - indeed, this deficit cannot be ruled out for many of our SA patients who showed impaired repetition. This difference between SA and SD would tend to work against the disparity in cueing that we observed and does not provide an alternative explanation of our results. However, if we had examined stroke aphasic patients with poor phonology as well as impaired comprehension (i.e. Wernicke's aphasia), we might have observed less clear differences between SD and SA. This is because the degree to which cues can overcome deficits in semantic control

\section{Acknowledgements}

We are indebted to the patients and their carers for their generous assistance with this study. We would also like to thank John Hodges, Roy Jones, Mark Doran, Rachel Byrne, Linda Collier and Claire Slinger for referring some of the patients to us. We gratefully acknowledge Peter Garrard's assistance with the interpretation of the brain scans and Karen Sage's help with classifying the stroke patients' aphasic syndromes. This work was supported by a grant from the NIMH (MH64445), an RCUK fellowship awarded to E. Jefferies and an MRC programme grant (G0501632).

\section{Appendix A. Lexical properties for the items included in the progressive phonological cueing experiment}

\begin{tabular}{|c|c|c|c|c|c|c|c|c|c|c|c|}
\hline \multicolumn{4}{|c|}{ One syllable } & \multicolumn{4}{|c|}{ Two syllable } & \multicolumn{4}{|c|}{ Three syllable } \\
\hline Item & $\begin{array}{l}\text { Rated } \\
\text { familiarity }\end{array}$ & $\begin{array}{l}\text { Celex } \\
\text { frequency }\end{array}$ & $\begin{array}{l}\text { Objective } \\
\text { AoA }\end{array}$ & Item & $\begin{array}{l}\text { Rated } \\
\text { familiarity }\end{array}$ & $\begin{array}{l}\text { Celex } \\
\text { frequency }\end{array}$ & $\begin{array}{l}\text { Objective } \\
\text { AoA }\end{array}$ & Item & $\begin{array}{l}\text { Rated } \\
\text { familiarity }\end{array}$ & $\begin{array}{l}\text { Celex } \\
\text { frequency }\end{array}$ & $\begin{array}{l}\text { Objective } \\
\text { AoA }\end{array}$ \\
\hline Sledge & 1.06 & 1 & 86.5 & Camel & 1.22 & 25 & 68.5 & Kangaroo & 1.17 & 3 & 44.5 \\
\hline Mouse & 2.00 & 18 & 23.4 & Barrel & 2.22 & 21 & 74.5 & Elephant & 2.17 & 24 & 23.4 \\
\hline Cow & 2.61 & 40 & 23.4 & Rabbit & 2.39 & 19 & 22.1 & Piano & 2.22 & 27 & 44.5 \\
\hline Swan & 3.00 & 7 & 62.5 & Cherry & 3.06 & 7 & 74.5 & Pineapple & 2.83 & 3 & 74.5 \\
\hline Duck & 3.06 & 14 & 22.1 & Lorry & 3.17 & 13 & 44.5 & Strawberry & 3.44 & 6 & 44.5 \\
\hline Stool & 3.83 & 12 & 50.5 & Basket & 3.61 & 24 & 38.5 & Bicycle & 3.67 & 23 & 23.4 \\
\hline Pear & 4.00 & 6 & 44.5 & Hammer & 3.89 & 11 & 25.1 & Aeroplane & 4.06 & 12 & 23.4 \\
\hline Plug & 4.33 & 9 & 68.5 & Scissors & 4.28 & 4 & 23.4 & Banana & 4.56 & 8 & 23.4 \\
\hline Brush & 4.39 & 17 & 23.4 & Dustbin & 4.67 & 5 & 68.5 & Envelope & 4.61 & 24 & 68.5 \\
\hline Comb & 4.72 & 5 & 38.5 & Apple & 4.89 & 30 & 22.1 & Tomato & 4.78 & 14 & 68.5 \\
\hline Mean & 3.30 & 12.90 & 44.33 & Mean & 3.34 & 15.90 & 46.17 & Mean & 3.35 & 14.40 & 43.86 \\
\hline S.D. & 1.17 & 10.96 & 22.54 & S.D. & 1.16 & 9.16 & 23.06 & S.D. & 1.22 & 9.40 & 20.63 \\
\hline
\end{tabular}

AoA: age-of-acquisition.

will be contingent on the ability to process spoken cues in the first place.

Finally, we note that the SA patients showed cueing effects regardless of whether they had lesions affecting the left prefrontal cortex. Similarly, in our previous study, patients with infarcts to left prefrontal and temporoparietal regions were not distinguishable in any meaningful way (both apparently had failures of semantic control). This similarity might be explained by the fact that these brain regions are integral parts of a single distributed neural network underpinning the control of semantic cognition. Indeed, we know that these two regions are strongly interconnected via the arcuate and superior longitudinal fasciculi (Gloor, 1997; Parker et al., 2005). Although previous functional neuroimaging and neuropsychological studies have focussed on the role of the left prefrontal cortex in controlled semantic processing and lexical retrieval (Demb et al., 1995; Gold \& Buckner, 2002; Robinson, Blair, \& Cipolotti, 1998; Robinson, Shallice, \& Cipolotti, 2005; Thompson-Schill, D'Esposito, Aguirre, \& Farah, 1997; Thompson-Schill et al., 1998; Wagner, Pare-Blagoev, Clark, \& Poldrack, 2001), recent research suggests that both prefrontal and temporoparietal cortex make an essential contribution to cognitive control (see Peers et al., 2005).

\section{References}

Baayen, R. H., Piepenbrock, R., \& van Rijn, H. (1993). The CELEX lexical database [CD-ROM]. Philadelphia, PA: Linguistic Data Consortium, University of Pennsylvania.

Berthier, M. L. (2001). Unexpected brain-language relationships in aphasia: Evidence from transcortical sensory aphasia associated with frontal lobe lesions. Aphasiology, 15, 99-130.

Bozeat, S., Lambon Ralph, M. A., Patterson, K., Garrard, P., \& Hodges, J. R. (2000). Non-verbal semantic impairment in semantic dementia. Neuropsychologia, 38, 1207-1215.

Burgess, P., \& Shallice, T. (1996). Bizarre responses, rule detection and frontal lobe lesions. Cortex, 32, 241-259.

Burgess, P., \& Shallice, T. (1997). Hayling sentence completion test. Suffolk, England: Thames Valley Test Company.

Chertkow, H., Bub, D., Deaudon, C., \& Whitehead, V. (1997). On the status of object concepts in aphasia. Brain and Language, 58, 203-232.

Crutch, S. J., \& Warrington, E. K. (2005). Gradients of semantic relatedness and their contrasting explanations in refractory access and storage semantic impairments. Cognitive Neuropsychology, 22, 851-876.

Damasio, A. R. (1989). The brain binds entities and events by multiregional activation from convergence zones. Neural Computation, 1, 123-132.

Damasio, H., Tranel, D., Grabowski, T., Adolphs, R., \& Damasio, A. (2004). Neural systems behind word and concept retrieval. Cognition, 92, 179-229.

Dell, G. S., \& O'Seaghdha, P. G. (1992). Stages of lexical access in language production. Cognition, 42, 287-314. 
Dell, G. S., Schwartz, M. F., Martin, N., Saffran, E. M., \& Gagnon, D. A. (1997). Lexical access in aphasic and nonaphasic speakers. Psychological Review, 104, 801-838.

Demb, J. B., Desmond, J. E., Wagner, A. D., Vaidya, C. J., Glover, G. H., \& Gabrieli, J. D. E. (1995). Semantic encoding and retrieval in the left inferior prefrontal cortex: A functional MRI study of task difficulty and process specificity. Journal of Neuroscience, 15, 5870-5878.

Folstein, M. F., Folstein, S. E., \& McHugh, P. R. (1975). Mini-mental state: A practical method for grading the cognitive state of patients for the clinician. Journal of Psychiatric Research, 12, 189-198.

Forde, E., \& Humphreys, G. W. (1995). Refractory semantics in global aphasia: On semantic organization and the access-storage distinction in neuropsychology. Memory, 3, 265-307.

Foygel, D., \& Dell, G. S. (2000). Models of impaired lexical access in speech production. Journal of Memory and Language, 43, 182-216.

Funnell, E. (1995). Objects and properties: A study of the breakdown of semantic memory. Memory, 3, 497-518.

Gloor, P. (1997). The temporal lobe and the limbic system. Oxford: Oxford University Press.

Gold, B. T., \& Buckner, R. L. (2002). Common prefrontal regions coactivate with dissociable posterior regions during controlled semantic and phonological tasks. Neuron, 35, 803-812.

Goodglass, H. (1983). The assessment of aphasia and related disorders (2nd ed.). Philadelphia: Lea \& Febiger.

Graham, K., Patterson, K., \& Hodges, J. R. (1995). Progressive pure anomia: Insufficient activation of phonology by meaning. Neurocase, 1, 25-38.

Hart, J., \& Gordon, B. (1990). Delineation of single-word semantic comprehension deficits in aphasia with anatomical correlation. Annals of Neurology, 27, 226-231.

Hodges, J. R., Patterson, K., Oxbury, S., \& Funnell, E. (1992). Semantic Dementia: Progressive fluent aphasia with temporal-lobe atrophy. Brain, 115, 1783-1806.

Howard, D., \& Patterson, K. (1992). Pyramids and Palm Trees: A test of semantic access from pictures and words. Bury St. Edmunds, Suffolk: Thames Valley Test Company.

Jefferies, E., Baker, S. S., Doran, M., \& Lambon Ralph, M. A. (2007). Refractory effects in semantically impaired stroke aphasic patients. Neuropsychologia, 45, 1065-1079.

Jefferies, E., Jones, R. W., Bateman, D., \& Lambon Ralph, M. A. (2005). A semantic contribution to nonword recall? Evidence for intact phonological processes in semantic dementia. Cognitive Neuropsychology, 22, 183-212.

Jefferies, E., \& Lambon Ralph, M. A. (2006). Semantic impairment in stroke aphasia vs. semantic dementia: A case-series comparison. Brain, 129, 2132-2147.

Jefferies, E., Patterson, K., Bateman, D., Jones, R., \& Lambon Ralph, M. A. (2006). The natural history of "pure" late-stage semantic dementia. Neurocase, 12, 1-14.

Kaplan, E., Goodglass, H., \& Weintraub, S. (1983). Boston Naming Test. Philadelphia: Lea \& Febiger.

Kay, J., Lesser, R., \& Coltheart, M. (1992). Psycholinguistic Assessments of Language Processing in Aphasia (PALPA). Hove, UK: Lawrence Erlbaum Associates.

Lambon Ralph, M. A. (1998). Distributed versus localist representations: Evidence from a study of item consistency in a case of classical anomia. Brain and Language, 64, 339-360.

Lambon Ralph, M. A., Graham, K. S., Ellis, A. W., \& Hodges, J. R. (1998). Naming in semantic dementia-what matters? Neuropsychologia, 36, 775-784.

Lambon Ralph, M. A., Cipolotti, L., \& Patterson, K. (1999). Oral naming and oral reading: Do they speak the same language? Cognitive Neuropsychology, 16, 157-169.

Lambon Ralph, M. A., McClelland, J. L., Patterson, K., Galton, C. J., \& Hodges, J. R. (2001). No right to speak? The relationship between object naming and semantic impairment: Neuropsychological abstract evidence and a computational model. Journal of Cognitive Neuroscience, 13, 341-356.

Martin, A., Haxby, J. V., Lalonde, F. M., Wiggs, C. L., \& Ungerleider, L. G. (1995). Discrete cortical regions associated with knowledge of color and knowledge of action. Science, 270, 102-105.
Milner, B. (1964). Effects of different brain lesions on card sorting: The role of the frontal lobes. Archives of Neurology, 9, 100-110.

Mummery, C. J., Patterson, K., Price, C. J., Ashburner, J., Frackowiak, R. S. J., \& Hodges, J. R. (2000). A voxel-based morphometry study of semantic dementia: Relationship between temporal lobe atrophy and semantic memory. Annals of Neurology, 47, 36-45.

Myers Pease, D., \& Goodglass, H. (1978). The effects of cueing on picture naming in aphasia. Cortex, 14, 178-189.

Nestor, P. J., Fryer, T. D., \& Hodges, J. R. (2006). Declarative memory impairments in Alzheimer's disease and semantic dementia. Neuroimage, 30, 1010-1020.

Parker, G. J. M., Luzzi, S., Alexander, D. C., Wheeler-Kingshott, C. A. M., Clecarelli, O., \& Lambon Ralph, M. A. (2005). Lateralization of ventral and dorsal auditory-language pathways in the human brain. Neuroimage, 24, 656-666.

Patterson, K., Purell, C., \& Morton, J. (1983). Facilitation of word retrieval in aphasia. In C. Code \& D. Muller (Eds.), Aphasia theory. London: Edward Arnold.

Peers, P. V., Ludwig, C. J. H., Rorden, C., Cusack, R., Bonfiglioli, C., Bundesen, C., et al. (2005). Attentional functions of parietal and frontal cortex. Cerebral Cortex, 15, 1469-1484.

Podraza, B. L., \& Darley, F. L. (1977). Effect of auditory prestimulation on naming in aphasia. Journal of Speech and Hearing Research, 20, 669683.

Raven, J. C. (1962). Coloured progressive matrices sets A, AB, B. London: H.K. Lewis.

Robertson, I. H., Ward, T., Ridgeway, V., \& Nimmo-Smith, I. (1994). The test of everyday attention. Flempton: Thames Valley Test Company.

Robinson, G., Blair, J., \& Cipolotti, L. (1998). Dynamic aphasia: An inability to select between competing verbal responses? Brain, 121, 77-89.

Robinson, G., Shallice, T., \& Cipolotti, L. (2005). A failure of high level verbal response selection in progressive dynamic aphasia. Cognitive Neuropsychology, 22, 661-694.

Rogers, T. T., Lambon Ralph, M. A., Garrard, P., Bozeat, S., McClelland, J. L., Hodges, J. R., et al. (2004). The structure and deterioration of semantic memory: A neuropsychological and computational investigation. Psychological Review, 111, 205-235.

Saffran, E. M. (2000). The organization of semantic memory: In support of a distributed model. Brain and Language, 71, 204-212.

Saygin, A. P., Dick, F., Wilson, S. M., Dronkers, N., \& Bates, E. (2003). Neural resources for processing language and environmental sounds. Brain, 126, 928-945.

Schwartz, M. F., Dell, G. S., Martin, N., Gahl, S., \& Sobel, P. (2006). A caseseries test of the interactive two-step model of lexical access: Evidence from picture naming. Journal of Memory and Language, 54, 228-264.

Snodgrass, J. G., \& Vanderwart, M. (1980). A standardized set of 260 pictures: Norms for name agreement, image agreement, familiarity and visual complexity. Journal of Experimental Psychology: Human Learning and Memory, 6, 174-215.

Snowden, J. S., Goulding, P. J., \& Neary, D. (1989). Semantic dementia: A form of circumscribed cerebral atrophy. Behavioural Neurology, 2, 167-182.

Stuss, D. T., Levine, B., Alexander, M. P., Hong, J., Palumbo, C., Hamer, L., et al. (2000). Wisconsin Card Sorting Test performance in patients with focal frontal and posterior brain damage: Effects of lesion location and test structure on seperable cognitive processes. Neuropsychologia, 34, 388402.

Thompson-Schill, S. L., D’Esposito, M., Aguirre, G. K., \& Farah, M. J. (1997). Role of left inferior prefrontal cortex in retrieval of semantic knowledge: A reevaluation. Proceedings of the National Academy of Sciences of the United States of America, 94, 14792-14797.

Thompson-Schill, S. L., Swick, D., Farah, M. J., D’Esposito, M., Kan, I. P., \& Knight, R. T. (1998). Verb generation in patients with focal frontal lesions: A neuropsychological test of neuroimaging findings. Proceedings of the National Academy of Sciences of the United States of America, 95, 15855-15860.

Wagner, A. D., Pare-Blagoev, E. J., Clark, J., \& Poldrack, R. A. (2001). Recovering meaning: Left prefrontal cortex guides controlled semantic retrieval. Neuron, 31, 329-338. 
Warrington, E. K., \& Cipolotti, L. (1996). Word comprehension: The distinction between refractory and storage impairments. Brain, 119, 611-625.

Warrington, E. K., \& James, M. (1991). The visual object and space perception battery. Bury St. Edmunds, Suffolk: Thames Valley Test Company.
Wechsler, D. (1987). Wechsler memory scale-revised (WMS-R). New York: Psychological Corporation.

Wernicke, C. (1874). Der Aphasische Symptomencomplex. Breslau: Cohn and Weigert. 